\title{
Critical ACE2 Determinants of SARS-CoV-2 and Group 2B Coronavirus Infection and Replication
}

\author{
(D) Lily E. Adams, ${ }^{a}$ Kenneth H. Dinnon III, ${ }^{\text {Y Yixuan J. Hou, }}{ }^{b}$ Timothy P. Sheahan, ${ }^{b}$ (D) Mark T. Heise, ${ }^{\text {a,c,d }}$ (D) Ralph S. Baric ${ }^{a, b, d}$ \\ aDepartment of Microbiology \& Immunology, University of North Carolina at Chapel Hill, Chapel Hill, North Carolina, USA \\ bDepartment of Epidemiology, University of North Carolina at Chapel Hill, Chapel Hill, North Carolina, USA \\ cDepartment of Genetics, University of North Carolina at Chapel Hill, Chapel Hill, North Carolina, USA \\ dRapidly Emerging Antiviral Drug Discovery Initiative, University of North Carolina, Chapel Hill, North Carolina, USA
}

ABSTRACT The angiotensin-converting enzyme 2 (ACE2) receptor is a major severe acute respiratory syndrome coronavirus 2 (SARS-CoV-2) host range determinant, and understanding SARS-CoV-2-ACE2 interactions will provide important insights into COVID-19 pathogenesis and animal model development. SARS-CoV-2 cannot infect mice due to incompatibility between its receptor binding domain and the murine ACE2 receptor. Through molecular modeling and empirical in vitro validation, we identified 5 key amino acid differences between murine and human ACE2 that mediate SARS-CoV-2 infection, generating a chimeric humanized murine ACE2. Additionally, we examined the ability of the humanized murine ACE2 receptor to permit infection by an additional preemergent group 2B coronavirus, WIV-1, providing evidence for the potential pan-virus capabilities of this chimeric receptor. Finally, we predicted the ability of these determinants to inform host range identification of preemergent coronaviruses by evaluating hot spot contacts between SARS-CoV-2 and additional potential host receptors. Our results identify residue determinants that mediate coronavirus receptor usage and host range for application in SARSCoV-2 and emerging coronavirus animal model development.

IMPORTANCE SARS-CoV-2 (the causative agent of COVID-19) is a major public health threat and one of two related coronaviruses that have caused epidemics in modern history. A method of screening potential infectible hosts for preemergent and future emergent coronaviruses would aid in mounting rapid response and intervention strategies during future emergence events. Here, we evaluated determinants of SARS-CoV-2 receptor interactions, identifying key changes that enable or prevent infection. The analysis detailed in this study will aid in the development of model systems to screen emergent coronaviruses as well as treatments to counteract infections.

KEYWORDS COVID-19, SARS-CoV-2, coronavirus, host range, receptors, virus-host interactions

\footnotetext{
ince its emergence in December 2019, severe acute respiratory syndrome coronavirus 2 (SARS-CoV-2) has infected tens of millions, leading to over 2 million deaths worldwide (1, 2). SARS-CoV-2, SARS-CoV (3), and other related group 2B coronaviruses poised for emergence (4) primarily utilize cellular angiotensin-converting enzyme 2 (ACE2) via the viral receptor binding domain (RBD) for entry. Zoonotic coronaviruses like SARS-CoV-2 emerge following a transmission event between reservoir species and a new permissive host where factors like RBD-receptor interactions and host proteases support infection. Although emergent and preemergent coronaviruses have been demonstrated to utilize ACE2 from multiple species in addition to the purported natural host, the mechanisms of these interactions are largely unknown, complicating
}

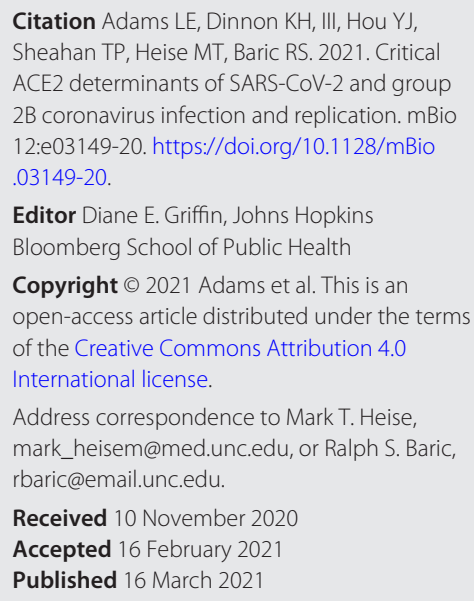


reservoir species identification and disease potential in mammals. The identification and characterization of key molecular interactions between specific RBD and ACE2 molecules could be applied to predict and determine the plasticity of the virus host range.

In addition to providing new insights into coronavirus receptor interactions and host range, characterizing determinants of ACE2 species restriction also has implications for SARS-CoV-2 animal model development. Mouse models have been essential for understanding the pathogenesis of coronaviruses and have been key resources for the preclinical development of vaccines and antiviral therapies (5-7). However, standard laboratory mice are not permissive to SARS-CoV-2 infection due to incompatible interactions between the RBD and the mouse ACE2 receptor (mACE2) (8), which is a substantial barrier to vaccine and antiviral development. While human ACE2 (hACE2) mouse models (9-13) and mouse-adapted viruses (14-16) have been developed, limitations exist. For example, hACE2 transgenic mice are permissive for nonadapted SARS-CoV-2 viruses, but the pathogenesis in these mice, with mortality driven by virusinduced encephalitis and multiorgan infection, is not representative of that observed in humans $(10,11,13)$. Additionally, mouse-adapted viruses contain amino acid changes and do not fully reflect circulating virus strains. The development of immunocompetent models that more faithfully model human pathogenesis will facilitate more robust and rigorous evaluations of vaccines, antibodies, and therapeutics. To map the SARS-CoV-2 RBD and mACE2 interaction network, we created a panel of mACE2 receptors with increasing levels of humanizing mutation based on predictive structural modeling, thus identifying the minimum changes necessary to restore replication.

Based on previous SARS-CoV research and published structures $(17,18)$, we identified likely SARS-CoV-2 RBD and ACE2 interactions via molecular modeling experiments. The ACE2 interaction residues support the presence of three hot spots: position K353 interacts with SARS-CoV-2 binding residues G496, N501, and Y505, position K31 forms a salt bridge with ACE2 residue K353 and interacts with SARS-CoV-2 Q493 and Y489, and position M82 interacts with RBD residues F486, N487, and Y489 (Fig. 1a and b). These interface hot spots are critical molecular constraints for receptor interaction and entry, and divergent residues at these sites are predicted to significantly decrease binding between mACE2 and SARS-CoV-2 RBD (8).

In order to evaluate the impact of mACE2 humanization at each of these interaction hot spots, we first modeled the interaction between SARS-CoV-2 RBD and mACE2 (Fig. 1c). From this, we predict that molecular incompatibility between the SARS-CoV-2 RBD and mACE2 may result in a profound loss of contact between mACE2 and the SARS-CoV-2 RBD residues Q493 and G496. We predict this significantly contributes to receptor incompatibility. We then modeled mutant mACE2 receptors that contain human residues that are predicted to reestablish increasing degrees of contacts, termed hmACE2.1 through hmACE2.4 (Fig. 1d to g) to identify and predict the changes that would mitigate this contact loss. We predict that the single amino acid change H353K in mACE2 can reestablish lost contacts (hmACE2.1). However, this mutation may inappropriately remodel contact between mACE2 hot spot residue 31 and SARSCoV-2 RBD F456 and Y489 residues, leading to loss of function. Mutations of N31K, S82M, and H353K in the mACE2 backbone (hmACE2.2) are predicted to reestablish the contacts with those lost from H353K but fail to maintain contact with G496. By introducing an additional two mutations to balance charges and conformations, N30D and F83Y (hmACE2.3), all lost contacts are predicted to be reestablished, producing a fully humanized mACE2. Additionally in this model, SARS-CoV2 RBD-ACE2 interactions reestablished by the above five amino acid changes (N30D, N31K, S82M, F83Y, and H353K) in hmACE2.3 are the same contacts reestablished by a swap of the entire mACE2 binding interface with that of hACE2 (hmACE2.4).

To experimentally test these models, a panel of hmACE2 receptors was generated to directly evaluate whether these predicted contact residues are essential for SARSCoV-2 infection. The receptors were introduced into mouse delayed brain tumor 
a

\begin{tabular}{|c|c|c|c|c|c|c|c|c|c|c|c|}
\hline AAN & 20 & 21 & 24 & 30 & 32 & 34 & 40 & 82 & 83 & 329 & 353 \\
\hline MACE2 2 & l & $T$ & $\mathrm{~N}$ & $\mathbf{N}$ & $\mathbf{N}$ & a & $S$ & $S$ & $\mathrm{~F}$ & A & H \\
\hline hmACE2.1 & & & & & & & & & & & K \\
\hline hmACE2.2 & & & & & K & & & $M$ & & & \\
\hline hmACE2.3 & & & & D & & & & & $Y$ & & \\
\hline hMACE2.4 & $T$ & 1 & Q & & & H & $\mathbf{F}$ & & & E & \\
\hline hACE2 & & & & & & & & & & & \\
\hline
\end{tabular}

b

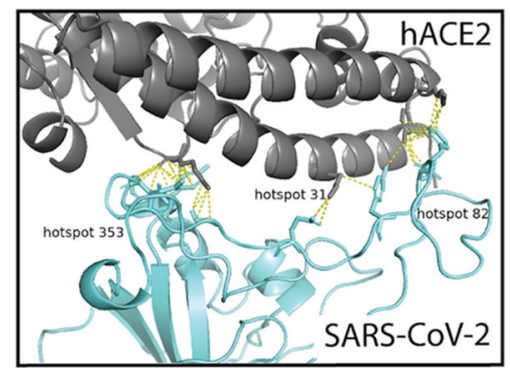

e

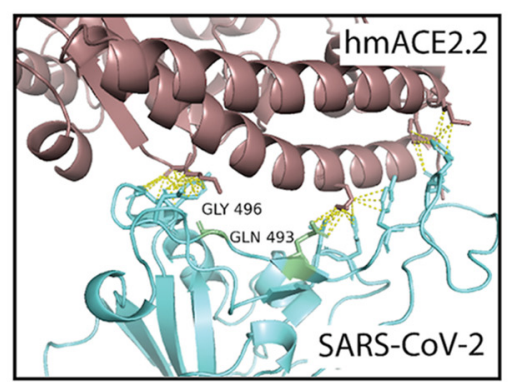

h

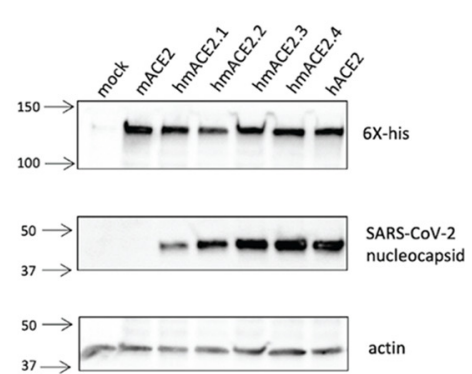

k

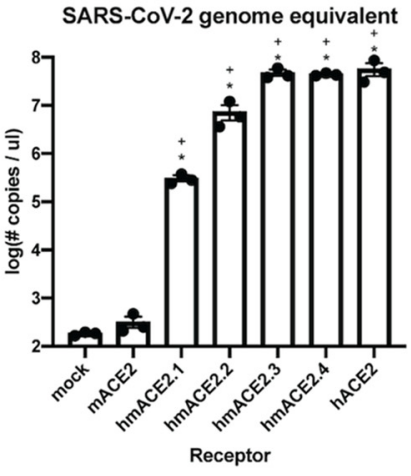

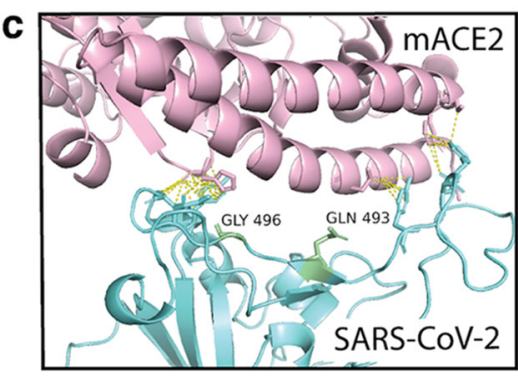
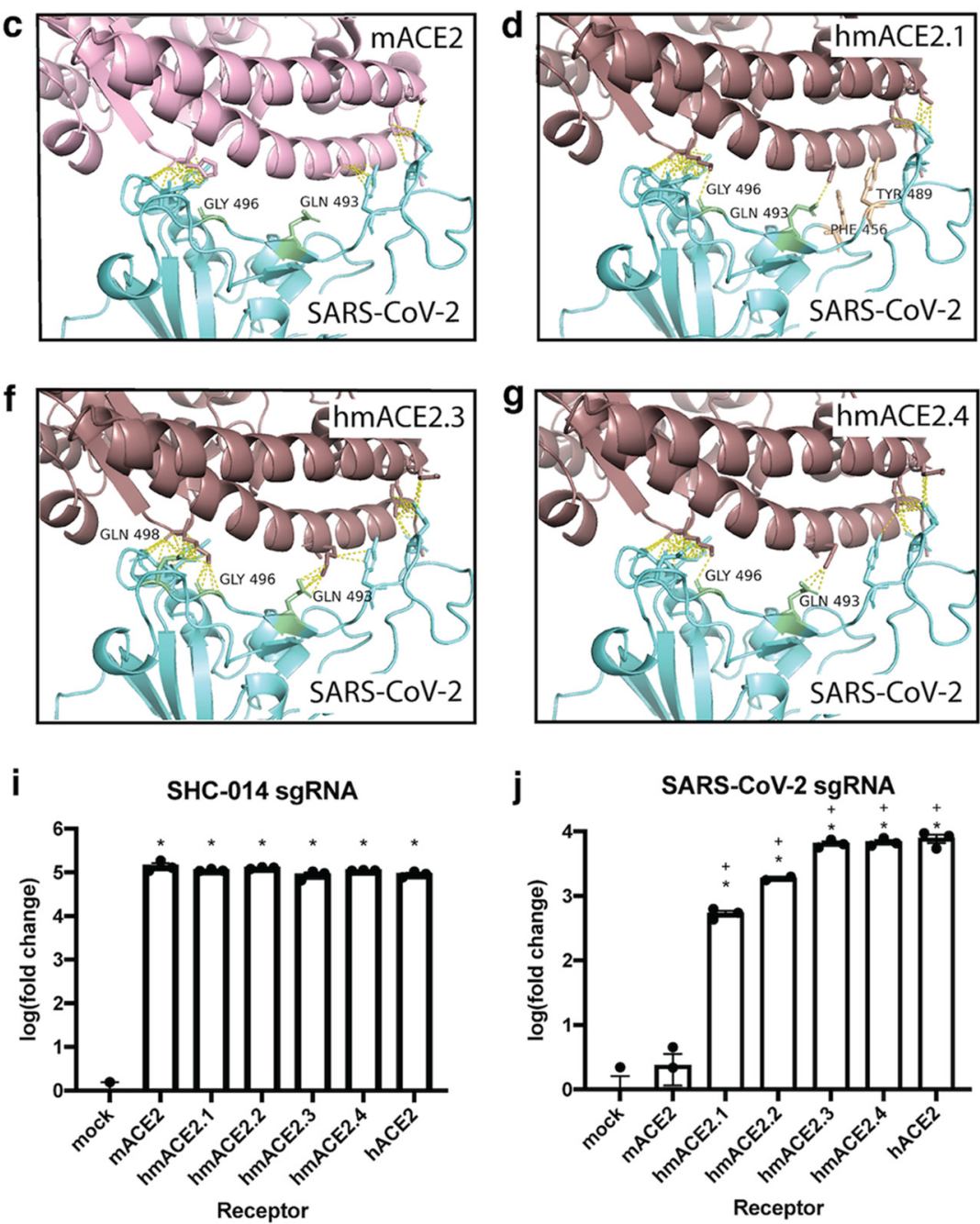

I

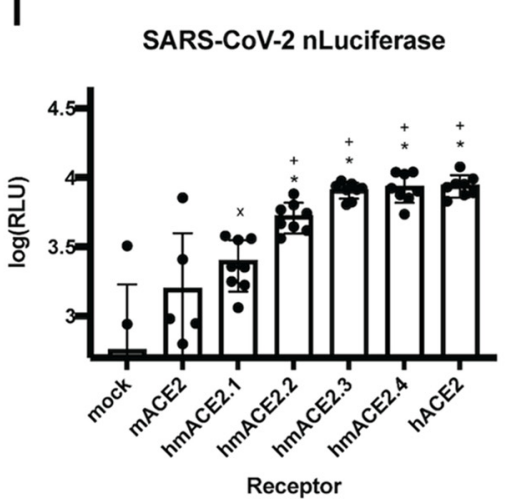

m

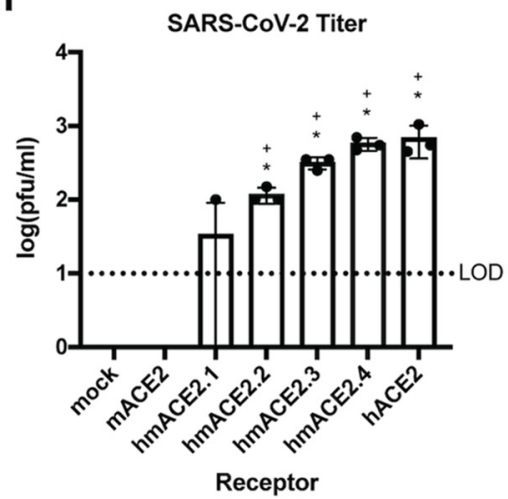

FIG 1 Engineered mutations in the mACE2 background reestablish contacts with SARS-CoV-2 RBD and support SARS-CoV-2 infection and replication. (a) Residues modified to incrementally increase humanization of mACE2 (blue, mouse; pink, human). (b) Contacts between the SARS- 
astrocytoma (DBT-9) cells $(19,20)$, normally nonpermissive for SARS-CoV-2 infection, and the cells were then infected with SARS-CoV-2 to test each chimeric receptor's ability to mediate infection. Expression of each receptor and detection of viral particles were confirmed by Western blotting (Fig. 1h). Infection of the receptor panel by preepidemic SARS-like bat CoV SHC014, which does not grow in unmodified DBT cells $(4,21)$ but utilizes both mACE2 and hACE2 equally, was employed as a functional positive control (Fig. 1i). We found that all of the receptors supported SHC014 infection equivalently, indicating functionally equivalent receptor surface expression. The viruses used were derived from molecular clones that, due to the proofreading capability of the coronavirus Nsp14, undergo low rates of mutation $(22,23)$. Consequently, our study was designed to only sample after a single round of replication and is unlikely to amplify, detect, or be influenced by rare variants that emerge due to binding effect. As quantified by quantitative PCR (qPCR) and viral titer, we found that all humanized receptors supported SARS-CoV-2 entry and replication, while wild-type (WT) mACE2 did not. We found that mACE2 facilitated isolated instances of SARS-CoV-2 entry as quantified by luciferase assay, but the positivity is likely due to background luminescence emitted during the assay. While a single change at position 353 was sufficient to support SARSCoV-2 infection by the mACE2 molecule, all five amino acid changes balancing the three binding hot spots were required to support efficient infection at levels comparable to hACE2, suggesting that satisfaction of interactions with the three hot spots are required for maximal infection. There was no significant increase in infection of hmACE2 remodeled to reflect the entire hACE2 binding interface past the remodeling of the five hot spot residues (Fig. $1 \mathrm{j}$ to $\mathrm{m}$ ). As such, we determined that additional mutations past the five to satisfy the hot spots were not necessary.

Given the importance of the three ACE2 interaction hot spots for SARS-CoV-2 infection, we asked whether these same determinants were important for infection by other preepidemic group 2B coronaviruses. We modeled interactions between hmACE2.3 and two related group 2B CoVs, preepidemic SARS-like bat CoV WIV-1 (4) and pangolin CoV, designated P5L (Fig. 2a), a group 2B pangolin virus closely related to SARS-CoV-2 (24). Our analysis indicates that, though the RBDs of the viruses are divergent past the hot spot-interacting residues (Fig. S3), both the P5L and WIV-1 RBD likely interact with the three ACE2 hot spots predicted to mediate receptor binding, indicating that these interactions may be generally important for receptor binding by SARS-CoV- and SARSCoV-2-like viruses (Fig. $2 \mathrm{~b}$ to e). To further test this, we evaluated our panel of chimeric mACE2 receptors for their ability to enhance WIV-1 murine receptor usage. Consistent with earlier findings (4), we show that WIV-1 can utilize mACE2; however, the presence of the 5 amino acid changes that restored the three binding hot spots significantly increased WIV-1 infection yields to levels that were comparable to cells expressing human ACE2 (Fig. $2 \mathrm{f}$ to $\mathrm{g}$ ). Though WIV-1 replicated to higher titers in this assay than SARS-CoV-2, there are other differences between these viruses that may result in enhanced replication by WIV-1. Therefore, the logical interpretation is that the presence of the humanized chimeras resulted in higher rates of infection over mACE2. This indicates that these interaction hot spots are broadly important for receptor recognition by SARS-CoV- and SARS-CoV-2-like group 2B coronaviruses and that the interactions predicted are favorable for productive infection.

Recent work has identified ACE2 variants from myriad mammalian species that support SARS-CoV-2 infection $(25,26)$, both for model development and as potential reser-

FIG 1 Legend (Continued)

CoV-2 RBD and the three hACE2 interaction hot spots. (c) Lost contacts between mACE2 hot spots and SARS-CoV-2 RBD Q493/G496 (red). (d to g) Key contacts gained and lost through mACE2 humanization of one amino acid change (Q493 and G496 gained, F456 and Y489 lost) (d), three amino acid changes (Q493, F456, and Y489 maintained, G496 lost) (e), five amino acid changes (all regained) ( $\mathrm{f}$ ), and a swap of the entire hACE2 binding interface (all maintained) (g). (h) Western blotting confirming ACE2 receptor expression (anti-6x-His) and SARS-CoV-2 (anti-nucleocapsid) infection. (i) qPCR $24 \mathrm{~h}$ after infection by SARS-like virus SHC014. (j) qPCR. (k) Genome equivalents. (I) Luciferase. (m) Titer $24 \mathrm{~h}$ following virus infection. $n=3$ replicates per sample. Data analyzed by 2-way analysis of variance (ANOVA) followed by Dunnett's multiple comparisons. Error bars represent standard error about the mean. " , comparisons to mock where $P \leq 0.0001$; $\mathrm{x}$, comparisons to mock where $P \leq 0.001$; + , comparisons to mACE2 where $P \leq 0.0001$. sgRNA, single guide RNA. 


\begin{tabular}{|cccccccccc|}
\hline SARS-CoV-2 AA\# & 456 & 486 & 487 & 489 & 493 & 496 & 498 & 501 & 505 \\
\hline SARS-CoV-2 & F & F & N & Y & Q & G & Q & N & Y \\
\hline P5L & F & L & N & Y & E & G & H & T & Y \\
\hline WIV1 & L & A & F & C & L & Y & F & T & G \\
\hline SARS-CoV & L & L & N & Y & N & G & Y & T & Y \\
\hline SARS-CoV AA \# & 443 & 472 & 473 & 475 & 479 & 482 & 484 & 487 & 491 \\
\hline
\end{tabular}

b

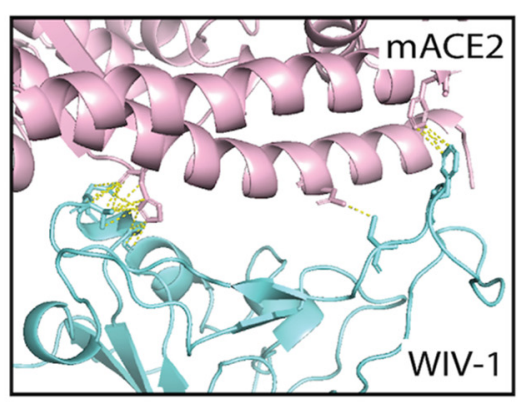

C

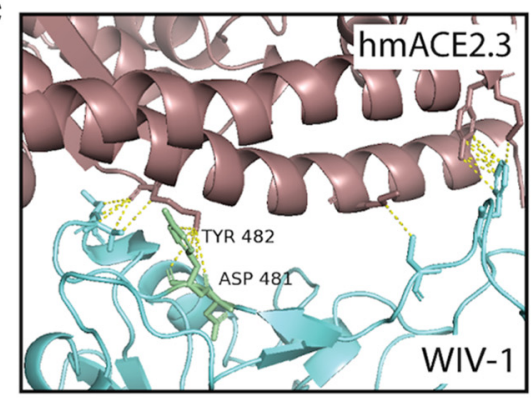

f
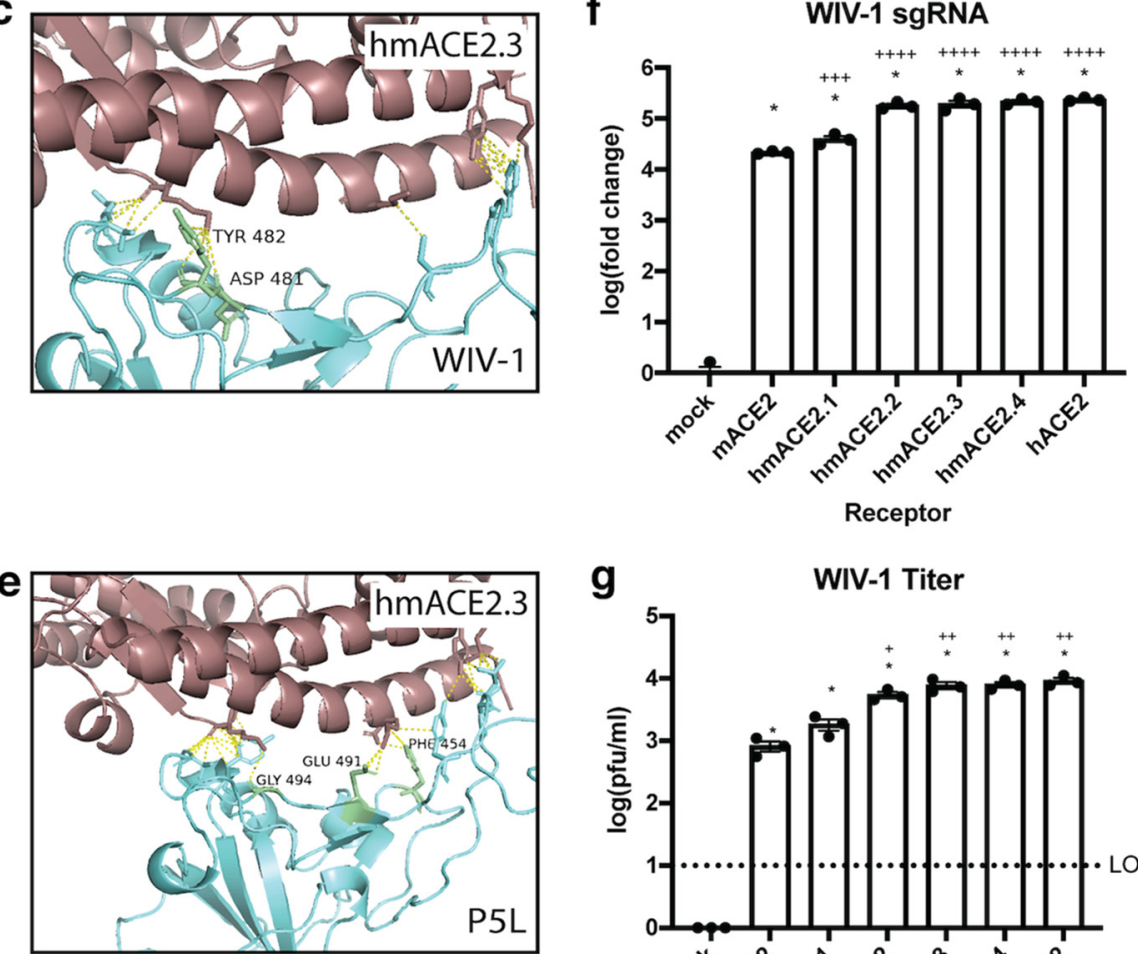

g

WIV-1 Titer

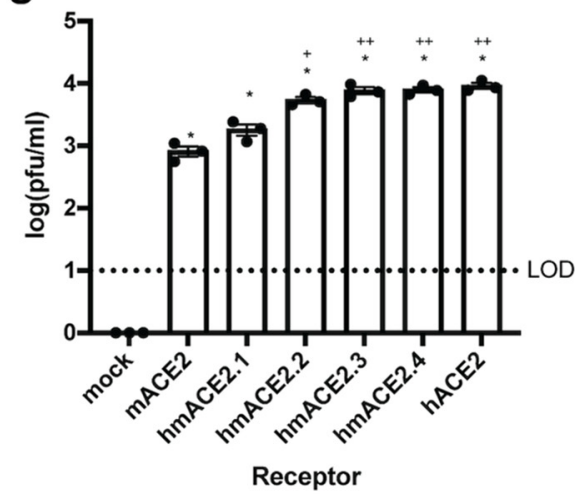

FIG 2 hmACE2 contacts with WIV-1 and P5L are predicted to support replication. (a) Aligned contact residues of SARS-CoV-2, SARS-CoV, WIV-1, and P5L. (b and c) Contacts identified between mACE2 and WIV-1 (b) and those gained between hmACE2 and WIV-1 (c) include Y482 and D481. (d and e) Contacts identified between mACE2 and P5L (d) and gained between hmACE2 and P5L (e) include G496, E493, and F456 (right). (f and g) qPCR ( $)$ and titer (g) $24 \mathrm{~h}$ following WIV-1 infection. Data analyzed by 2-way ANOVA followed by Dunnett's multiple comparisons. Error bars represent standard error about the mean. ${ }^{*}$, comparisons to mock where $P \leq 0.0001$. Plus signs represent comparisons to $\mathrm{mACE} 2(+, P \leq 0.05 ;++, P \leq 0.01 ;+++, P \leq 0.001 ;++++$, $P \leq 0.0001)$.

voirs. Though ACE2 variant sequences are divergent, we asked whether the sequence homology was sufficient to model the interactions between these host receptors and the SARS-CoV-2 RBD. Based on pairwise sequence alignments to hACE2 (Fig. S2), we modeled the RBD interaction with ACE2 molecules from species reported to support entry and infection in vitro (ferret, macaque, mink, cat, pig, guinea pig, and dog) as well as those from species reported to support little to no infection (mouse, chicken) (Fig. S1) $(25,27)$. The molecular interactions, both favorable and unfavorable, we predicted align with the differences in infection identified in recent work. For example, though human and ferret ACE2 differ at residue 81, we predict the SARS-CoV-2 RBD still interacts favorably with ferret ACE2 to satisfy the three critical interaction hot spots. Conversely, though chicken ACE2 contains hot spot residue K353, we predict molecular incompatibility due to lack of contact at hot spot 31. Furthermore, ACE2 molecules from other highly susceptible species are homologous in some (cats) or all 
(nonhuman primates) hot spot residues, which enable contact between the three hot spots and the SARS-COV-2 RBD (8), providing further support that the hot spot analysis is highly informative. Our predictions indicate that the three hot spots may be used to accurately predict the receptor interaction between ACE2 and group 2B coronaviruses and that the sequence homology between ACE2 molecules is sufficient to model these interactions in instances where no experimentally determined structure is available. This enables a molecular modeling-based screening approach to host range predictions. Furthermore, while additional work has found that some animals predicted to be reservoirs to SARS-CoV-2 infection are not permissive in vivo $(27,28)$, all of the animals predicted to not be infectible based on receptor interaction have been identified as nonpermissive hosts. This shows that, while favorable receptor interaction may not be sufficient for productive infection, it is a primary determinant of host range. Additionally, this work demonstrates that this contact analysis can be used to rapidly filter ACE2 molecules from different species to identify or eliminate potential reservoir hosts or animal models.

Our results provide key insights into the amino acid differences between human and mouse ACE2 molecules that are responsible for determining SARS-CoV-2 receptor activity and species specificity. In mouse-adapted viruses, mACE2 binding was restored by the single mutations Q498H (29), N501Y (16), Q498Y (14), and Q493K (15), demonstrating several pathways to increased mACE2 usage. Recent work has also identified various isolates able to infect mink that contain RBD substitution Y453F, which likely improves contact with hot spot 31 in the mink ACE2 molecule and appear to retain contact with all hot spots in human ACE2 (30). Furthermore, emerging variants from Africa and London contain substitution N501Y, an RBD substitution that likely improves contact with both mouse ACE2 and human ACE2, due to biochemical and structural property changes at hot spot 353 . These data (supplemental material) support our findings that interactions at single hot spots enhance usage, leading to multiple evolutionary pathways to adaptation, but efficient adaptation may require multiple mutations that allow for efficient usage of multiple hot spots. We also identified key contact residues within ACE2 that mediate receptor interactions with other epidemic and preepidemic group 2B coronaviruses. Given the importance of these interactions for SARS-CoV-2 infection, we suggest that these determinants may be used to also predict susceptible species for model development or reservoir formation. Furthermore, it should be possible to introduce these changes into the mACE2 gene in vivo by gene editing (31), thereby generating a chimeric ACE2 receptor with physiologic expression patterns that is capable of mediating infection by clinical isolates of SARS-CoV-2 and potentially preemergent group 2B coronaviruses. This work did not address, however, the influence of ACE2 isoforms or allelic variants on host susceptibility, including cytokine-inducible ACE2 variants or variation in ACE2 expression levels $(32,33)$. In addition to isoform expression, host factors like protease state also significantly impact cellular susceptibility to SARS-CoV-2 $(34,35)$, as evidenced by conflicting results between in vitro assays and in vivo infection to identify potential SARS-CoV-2 reservoir species and animal models $(25,26,28)$. We have found that favorable receptor interaction is absolutely necessary for productive infection, consonant with earlier findings (36), but all potential hosts must be fully evaluated in downstream analysis to investigate additional factors determining host range.

Molecular modeling and visualization. The ACE2 panel was aligned using Geneious Prime (version 2020.0.5). The hACE2 sequence is found under GenBank accession no. BAB40370 and mACE2 sequence under GenPept accession no. NP _081562. Scores were computed using BLOSUM62 scoring matrix. Three-dimensional structures were predicted using MODELLER homology modeling tool (37) from pairwise sequence alignment to the reference SARS-CoV-2 RBD hACE2 complex (PDB ID 6M0J) and SARS-CoV RBD hACE2 complex (PDB ID 2AJF). WIV-1 RBD was modeled using the reference sequence, GenPept accession no. AGZ48828.1, and P5L RBD was modeled 
TABLE 1 Primers and sequences used in this study

\begin{tabular}{ll}
\hline Primer & Sequence \\
\hline SARS-CoV-2 sgN F & $5^{\prime}$-TTCGATCTCTTGTAGATCTGTTCTC-3' \\
SARS-CoV-2 sgN R & $5^{\prime}$-GCGTCTCCATCTGGTTACT-3' \\
SARS-CoV-2 sgN probe & $5^{\prime}$-FAM-ACGTTGGTGGACCCTCAGATTCA-3' \\
SARS-CoV-2 Nsp4 F & $5^{\prime}$-GTGCTCATGGATGGCTCTATTA-3' \\
SARS-CoV-2 Nsp4 R & $5^{\prime}$-CGTGCCTACAGTACTCAGAATC-3' \\
SARS-CoV-2 Nsp4 probe & $5^{\prime}$-FAM-ACCTACCTTGAAGGTTCTGTTAGAGTGGT-3' \\
WIV1-CoV sgN F & $5^{\prime}$-CGATCTCTTGTAGATCTGTTCTCTAA-3' \\
WIV1-CoV sgN R & 5'-CTGTGGGTCCACCAAATGTA-3' \\
WIV1-CoV sgN probe & $5^{\prime}$-FAM-CCAATCAAACCAGCGTAGTGCCC-3' \\
\hline
\end{tabular}

using GenBank accession no. MT040335.1. Additional receptor interactions were modeled from the following translated reference sequences: chicken, GenBank accession no. XM_416822.5; guinea pig, GenBank accession no. XM_023562040.1; ferret, GenBank accession no. XM_004758886.2; pig, GenBank accession no. EU518378.1; dog, GenBank accession no. NM_001165260.1; macaque, GenBank accession no. NM_001135696.1; and mink, GenBank accession no. MT560518.1. Contacts were identified and visualized in the PyMOL molecular graphics system (Schrödinger LLC). Structure-based multiple sequence alignment was generated with UCSF Chimera.

Viruses and cells. All viruses were derived using infectious clone technology as previously described, including icSARS-CoV-2-WT (GenBank accession no. MT461669), icSARS-CoV-2-nLuc (GenBank accession no. MT461671) (38), and icWIV1-CoV (4) (GenBank accession no. KF367457.1). Mouse delayed brain tumor astrocytoma (DBT-9) $(19,20)$ cells were maintained in minimum essential medium (MEM; Gibco), 10\% fetal clone II serum (FCll; HyClone), and $1 \times$ antibiotic/antimycotic (Gibco). Vero E6 cells were maintained in Dulbecco's modified Eagle's medium (DMEM; Gibco), 5\% FC11, and $1 \times$ antibiotic/antimycotic.

ACE2 panel construction. Each mouse, human, and chimeric ACE2 was expressed in pCDNA3.1 vector that conjugates a C-terminal $6 \times-\mathrm{His}$ tag to the end of the expressed protein. The hmACE2 panel was generated with a combination of sitedirected mutagenesis and custom double-stranded gBlocks gene fragments (IDT). DBT9 cells were transfected using Lipofectamine 2000 transfection reagent (Invitrogen). Expression of each receptor was verified via staining against a $6 \times-\mathrm{His}$ epitope (Invitrogen; catalog no. PA1-983B) and Western blotting.

Infection and analysis. Cells were infected in triplicate $24 \mathrm{~h}$ posttransfection for receptor usage analysis at a multiplicity of infection (MOl) of 1 for $1 \mathrm{~h}$. Inoculum was removed, cells were washed with Dulbecco's phosphate-buffered saline (DPBS), and medium was replaced. Receptor usage was analyzed $24 \mathrm{~h}$ postinfection. RNA was collected via TRIzol (Invitrogen) and extracted using Direct-zol RNA MiniPrep kit (Zymo Research). Viral RNA was quantified in duplicate via reverse transcriptase quantitative PCR (qRT-PCR) using TaqMan Fast Virus 1-Step Master Mix (Thermo Fisher Scientific) on a QuantStudio 3 (Applied Biosystems). Viral RNA was quantified with a subgenomic diagnostic assay primer set (Table 1). Host 18S rRNA was used as housekeeping control (Invitrogen; catalog no. 4319413E). Viral RNA was analyzed using the threshold cycle $(\triangle \Delta C T)$ method and fold change over viral RNA in empty vector-transfected cells. SARS-CoV-2 genome equivalents were calculated against a standard curve with a diagnostic genomic assay primer set against Nsp4 (Table 1). Receptor expression was confirmed via Western blotting against the $6 \times-\mathrm{His}$ tag and virus nucleocapsid. For virus titer calculation, Vero E6 cells were infected at an MOI of 1 for $1 \mathrm{~h}$. Inoculum was removed, and the monolayer was washed with PBS and replaced with medium. The medium was removed $24 \mathrm{~h}$ postinfection and stored at $-80^{\circ} \mathrm{C}$ until the titer was determined by plaque assay. Briefly, virus was serial diluted and inoculated onto confluent monolayers of Vero E6 cells, followed by agarose overlay. Plaques were visualized on day 2 postinfection via staining with neutral red dye. 
Data availability. All relevant data sets generated or analyzed in this study have been included in the article. Additional information, including replicates, is available upon request.

\author{
SUPPLEMENTAL MATERIAL \\ Supplemental material is available online only. \\ FIG S1, TIF file, 1.1 MB. \\ FIG S2, TIF file, 0.7 MB. \\ FIG S3, TIF file, 1.5 MB.
}

\title{
ACKNOWLEDGMENTS
}

This project was funded in part by the National Institute of Allergy and Infectious Diseases, National Institutes of Health, Department of Health and Human Service awards 1R01 AI089728, U54 CA260543, and 1R01 Al110700. This project was supported in part by the North Carolina Policy Collaboratory at the University of North Carolina at Chapel Hill with funding from the North Carolina Coronavirus Relief Fund established and appropriated by the North Carolina General Assembly.

\section{REFERENCES}

1. Wu F, Zhao S, Yu B, Chen Y-M, Wang W, Song Z-G, Hu Y, Tao Z-W, Tian J-H, Pei Y-Y, Yuan M-L, Zhang Y-L, Dai F-H, Liu Y, Wang Q-M, Zheng J-J, Xu L, Holmes EC, Zhang Y-Z. 2020. A new coronavirus associated with human respiratory disease in China. Nature 579:265-269. https://doi.org/10 .1038/s41586-020-2008-3.

2. Zhou P, Yang X-L, Wang X-G, Hu B, Zhang L, Zhang W, Si H-R, Zhu Y, Li B, Huang C-L, Chen H-D, Chen J, Luo Y, Guo H, Jiang R-D, Liu M-Q, Chen Y, Shen X-R, Wang X, Zheng X-S, Zhao K, Chen Q-J, Deng F, Liu L-L, Yan B, Zhan F-X, Wang Y-Y, Xiao G-F, Shi Z-L. 2020. A pneumonia outbreak associated with a new coronavirus of probable bat origin. Nature 579: 270-273. https://doi.org/10.1038/s41586-020-2012-7.

3. Andersen KG, Rambaut A, Lipkin WI, Holmes EC, Garry RF. 2020. The proximal origin of SARS-CoV-2. Nat Med 26:450-452. https://doi.org/10.1038/ s41591-020-0820-9.

4. Menachery VD, Yount BL, Sims AC, Debbink K, Agnihothram SS, Gralinski LE, Graham RL, Scobey T, Plante JA, Royal SR, Swanstrom J, Sheahan TP, Pickles RJ, Corti D, Randell SH, Lanzavecchia A, Marasco WA, Baric RS. 2016. SARS-like WIV1-CoV poised for human emergence. Proc Natl Acad Sci U S A 113:3048-3053. https://doi.org/10.1073/pnas.1517719113.

5. Sheahan TP, Sims AC, Zhou S, Graham RL, Pruijssers AJ, Agostini ML, Leist SR, Schäfer A, Dinnon KH, Stevens LJ, Chappell JD, Lu X, Hughes TM, George AS, Hill CS, Montgomery SA, Brown AJ, Bluemling GR, Natchus MG, Saindane M, Kolykhalov AA, Painter G, Harcourt J, Tamin A, Thornburg NJ, Swanstrom R, Denison MR, Baric RS. 2020. An orally bioavailable broad-spectrum antiviral inhibits SARS-CoV-2 in human airway epithelial cell cultures and multiple coronaviruses in mice. Sci Transl Med 12:eabb5883. https://doi.org/10.1126/scitranslmed.abb5883.

6. Pruijssers AJ, George AS, Schäfer A, Leist SR, Gralinksi LE, Dinnon KH, Yount BL, Agostini ML, Stevens $\sqcup$, Chappell JD, Lu X, Hughes TM, Gully K, Martinez DR, Brown AJ, Graham RL, Perry JK, Du Pont V, Pitts J, Ma B, Babusis D, Murakami E, Feng JY, Bilello JP, Porter DP, Cihlar T, Baric RS, Denison MR, Sheahan TP. 2020. Remdesivir Inhibits SARS-CoV-2 in human lung cells and chimeric SARS-CoV expressing the SARS-CoV-2 RNA polymerase in mice. Cell Rep 32:107940. https://doi.org/10.1016/j.celrep.2020.107940.

7. Agostini ML, Andres EL, Sims AC, Graham RL, Sheahan TP, Lu X, Smith EC, Case JB, Feng JY, Jordan R, Ray AS, Cihlar T, Siegel D, Mackman RL, Clarke MO, Baric RS, Denison MR. 2018. Coronavirus susceptibility to the antiviral remdesivir (GS-5734) is mediated by the viral polymerase and the proofreading exoribonuclease. mBio 9:e00221-18. https://doi.org/10.1128/ mBio.00221-18.

8. Wan Y, Shang J, Graham R, Baric RS, Li F. 2020. Receptor recognition by the novel coronavirus from Wuhan: an analysis based on decade-long structural studies of SARS coronavirus. J Virol 94:e00127-20. https://doi .org/10.1128/JVI.00127-20.

9. Hassan AO, Case JB, Winkler ES, Thackray LB, Kafai NM, Bailey AL, McCune BT, Fox JM, Chen RE, Alsoussi WB, Turner JS, Schmitz AJ, Lei T, Shrihari S, Keeler SP, Fremont DH, Greco S, McCray PB, Perlman S, Holtzman MJ,
Ellebedy AH, Diamond MS. 2020. A SARS-CoV-2 infection model in mice demonstrates protection by neutralizing antibodies. Cell 182:744-753.e4. https://doi.org/10.1016/j.cell.2020.06.011.

10. Sun S-H, Chen Q, Gu H-J, Yang G, Wang Y-X, Huang X-Y, Liu S-S, Zhang NN, Li X-F, Xiong R, Guo Y, Deng Y-Q, Huang W-J, Liu Q, Liu Q-M, Shen Y-L, Zhou Y, Yang X, Zhao T-Y, Fan C-F, Zhou Y-S, Qin C-F, Wang Y-C. 2020. A mouse model of SARS-CoV-2 infection and pathogenesis. Cell Host Microbe 28:124-133.e4. https://doi.org/10.1016/j.chom.2020.05.020.

11. Netland J, Meyerholz DK, Moore S, Cassell M, Perlman S. 2008. Severe acute respiratory syndrome coronavirus infection causes neuronal death in the absence of encephalitis in mice transgenic for human ACE2. J Virol 82:7264-7275. https://doi.org/10.1128/JVI.00737-08.

12. Israelow B, Song E, Mao T, Lu P, Meir A, Liu F, Alfajaro MM, Wei J, Dong H, Homer RJ, Ring A, Wilen CB, Iwasaki A. 2020. Mouse model of SARS-CoV-2 reveals inflammatory role of type I interferon signaling. J Exp Med 217: e20201241. https://doi.org/10.1084/jem.20201241.

13. Bao L, Deng W, Huang B, Gao H, Liu J, Ren L, Wei Q, Yu P, Xu Y, Qi F, Qu Y, Li F, Lv Q, Wang W, Xue J, Gong S, Liu M, Wang G, Wang S, Song Z, Zhao L, Liu P, Zhao L, Ye F, Wang H, Zhou W, Zhu N, Zhen W, Yu H, Zhang X, Guo L, Chen L, Wang C, Wang Y, Wang X, Xiao Y, Sun Q, Liu H, Zhu F, Ma C, Yan L, Yang M, Han J, Xu W, Tan W, Peng X, Jin Q, Wu G, Qin C. 2020. The pathogenicity of SARS-CoV-2 in hACE2 transgenic mice. Nature 583:830-833. https://doi.org/10.1038/s41586-020-2312-y.

14. Dinnon KH, Leist SR, Schäfer A, Edwards CE, Martinez DR, Montgomery SA, West A, Yount BL, Hou YJ, Adams LE, Gully KL, Brown AJ, Huang E, Bryant MD, Choong IC, Glenn JS, Gralinski LE, Sheahan TP, Baric RS. 2020. A mouseadapted model of SARS-CoV-2 to test COVID-19 countermeasures. Nature 586:560-569. https://doi.org/10.1038/s41586-020-2708-8.

15. Leist SR, Dinnon KH, Schäfer A, Tse LV, Okuda K, Hou YJ, West A, Edwards CE, Sanders W, Fritch EJ, Gully KL, Scobey T, Brown AJ, Sheahan TP, Moorman NJ, Boucher RC, Gralinski LE, Montgomery SA, Baric RS. 2020. A mouse-adapted SARS-CoV-2 induces acute lung injury (ALI) and mortality in standard laboratory mice. Cell 183:1070-1085. https://doi.org/10.1016/ j.cell.2020.09.050.

16. Gu H, Chen $Q$, Yang G, He L, Fan H, Deng $Y-Q$, Wang $Y$, Teng $Y$, Zhao Z, Cui Y, Li Y, Li X-F, Li J, Zhang N-N, Yang X, Chen S, Guo Y, Zhao G, Wang X, Luo D-Y, Wang H, Yang X, Li Y, Han G, He Y, Zhou X, Geng S, Sheng X, Jiang S, Sun S, Qin C-F, Zhou Y. 2020. Adaptation of SARS-CoV-2 in BALB/C mice for testing vaccine efficacy. Science 369:1603-1607. https://doi.org/ 10.1126/science.abc4730.

17. Lan J, Ge J, Yu J, Shan S, Zhou H, Fan S, Zhang Q, Shi X, Wang Q, Zhang L, Wang X. 2020. Structure of the SARS-CoV-2 spike receptor-binding domain bound to the ACE2 receptor. Nature 581:215-220. https://doi.org/ 10.1038/s41586-020-2180-5.

18. Shang J, Ye G, Shi K, Wan Y, Luo C, Aihara H, Geng Q, Auerbach A, Li F. 2020. Structural basis of receptor recognition by SARS-CoV-2. Nature 581:221-224. https://doi.org/10.1038/s41586-020-2179-y. 
19. Hirano N, Fujiwara K, Hino S, Matumoto M. 1974. Replication and plaque formation of mouse hepatitis virus (MHV-2) in mouse cell line DBT culture. Arch Gesamte Virusforsch 44:298-302. https://doi.org/10 1007/BF01240618.

20. Chen W, Baric RS. 1996. Molecular anatomy of mouse hepatitis virus persistence: coevolution of increased host cell resistance and virus virulence. J Virol 70:3947-3960. https://doi.org/10.1128/JVI.70.6.3947-3960.1996.

21. Menachery VD, Yount BL, Debbink K, Agnihothram S, Gralinski LE, Plante JA, Graham RL, Scobey T, Ge X-Y, Donaldson EF, Randell SH, Lanzavecchia A, Marasco WA, Shi Z-L, Baric RS. 2015. A SARS-like cluster of circulating bat coronaviruses shows potential for human emergence. Nat Med 21: 1508-1513. https://doi.org/10.1038/nm.3985.

22. Denison MR, Graham RL, Donaldson EF, Eckerle LD, Baric RS. 2011. Coronaviruses: an RNA proofreading machine regulates replication fidelity and diversity. RNA Biol 8:270-279. https://doi.org/10.4161/rna.8.2.15013.

23. Eckerle LD, Lu X, Sperry SM, Choi L, Denison MR. 2007. High fidelity of murine hepatitis virus replication is decreased in nsp14 exoribonuclease mutants. J Virol 81:12135-12144. https://doi.org/10.1128/JVI.01296-07.

24. Lam TT-Y, Jia N, Zhang Y-W, Shum MH-H, Jiang J-F, Zhu H-C, Tong Y-G, Shi Y-X, Ni X-B, Liao Y-S, Li W-J, Jiang B-G, Wei W, Yuan T-T, Zheng K, Cui X-M, Li J, Pei G-Q, Qiang X, Cheung WY-M, Li L-F, Sun F-F, Qin S, Huang JC, Leung GM, Holmes EC, Hu Y-L, Guan Y, Cao W-C. 2020. Identifying SARS-CoV-2-related coronaviruses in Malayan pangolins. Nature 583: 282-285. https://doi.org/10.1038/s41586-020-2169-0.

25. Conceicao C, Thakur N, Human S, Kelly JT, Logan L, Bialy D, Bhat S, Stevenson-Leggett $P$, Zagrajek AK, Hollinghurst $P$, Varga $M$, Tsirigoti $C$, Tully M, Chiu C, Moffat K, Silesian AP, Hammond JA, Maier HJ, Bickerton E, Shelton H, Dietrich I, Graham SC, Bailey D. 2020. The SARS-CoV-2 spike protein has a broad tropism for mammalian ACE2 proteins. PLoS Biol 18: e3001016. https://doi.org/10.1371/journal.pbio.3001016.

26. Li Y, Wang H, Tang X, Fang S, Ma D, Du C, Wang Y, Pan H, Yao W, Zhang R, Zou X, Zheng J, Xu L, Farzan M, Zhong G. 2020. SARS-CoV-2 and three related coronaviruses utilize multiple ACE2 orthologs and are potently blocked by an improved ACE2-lg. J Virol 94:e01283-20. https://doi.org/10 .1128/JVI.01283-20.

27. Schlottau K, Rissmann M, Graaf A, Schön J, Sehl J, Wylezich C, Höper D, Mettenleiter TC, Balkema-Buschmann A, Harder T, Grund C, Hoffmann D, Breithaupt A, Beer M. 2020. SARS-CoV-2 in fruit bats, ferrets, pigs, and chickens: an experimental transmission study. Lancet Microbe 1: e218-e225. https://doi.org/10.1016/S2666-5247(20)30089-6.

28. Shi J, Wen Z, Zhong G, Yang H, Wang C, Huang B, Liu R, He X, Shuai L, Sun Z, Zhao Y, Liu P, Liang L, Cui P, Wang J, Zhang X, Guan Y, Tan W, Wu G, Chen H, Bu Z. 2020. Susceptibility of ferrets, cats, dogs, and other domesticated animals to SARS-coronavirus 2. Science 368:1016-1020. https:// doi.org/10.1126/science.abb7015.

29. Wang J, Shuai L, Wang C, Liu R, He X, Zhang X, Sun Z, Shan D, Ge J, Wang X, Hua R, Zhong G, Wen Z, Bu Z. 2020. Mouse-adapted SARS-CoV-2 replicates efficiently in the upper and lower respiratory tract of BALB/C and
C57BL/6J mice. Protein Cell 11:776-782. https://doi.org/10.1007/s13238 $-020-00767-x$.

30. Oude Munnink BB, Sikkema RS, Nieuwenhuijse DF, Molenaar RJ, Munger E, Molenkamp $R$, van der Spek A, Tolsma $P$, Rietveld A, Brouwer $M$, Bouwmeester-Vincken N, Harders F, Hakze-van der Honing R, WegdamBlans MCA, Bouwstra RJ, GeurtsvanKessel C, van der Eijk AA, Velkers FC, Smit LAM, Stegeman A, van der Poel WHM, Koopmans MPG. 2021. Transmission of SARS-CoV-2 on mink farms between humans and mink and back to humans. Science 371:172-177. https://doi.org/10.1126/science .abe5901.

31. Cockrell AS, Yount BL, Scobey T, Jensen K, Douglas M, Beall A, Tang X-C, Marasco WA, Heise MT, Baric RS. 2017. A mouse model for MERS coronavirus-induced acute respiratory distress syndrome. 2. Nat Microbiol 2:1-11. https://doi.org/10.1038/nmicrobiol.2016.226.

32. Menachery VD, Eisfeld AJ, Schäfer A, Josset L, Sims AC, Proll S, Fan S, Li C, Neumann G, Tilton SC, Chang J, Gralinski LE, Long C, Green R, Williams CM, Weiss J, Matzke MM, Webb-Robertson B-J, Schepmoes AA, Shukla AK, Metz TO, Smith RD, Waters KM, Katze MG, Kawaoka Y, Baric RS. 2014. Pathogenic influenza viruses and coronaviruses utilize similar and contrasting approaches to control interferon-stimulated gene responses. mBio 5:e01174-14. https://doi.org/10.1128/mBio.01174-14.

33. Sang ER, Tian Y, Gong Y, Miller LC, Sang Y. 2020. Integrate structural analysis, isoform diversity, and interferon-inductive propensity of ACE2 to predict SARS-CoV2 susceptibility in vertebrates. Heliyon 6:e04818. https://doi.org/10.1016/j.heliyon.2020.e04818.

34. Menachery VD, Dinnon KH, Yount BL, McAnarney ET, Gralinski LE, Hale A, Graham RL, Scobey T, Anthony SJ, Wang L, Graham B, Randell SH, Lipkin WI, Baric RS. 2019. Trypsin treatment unlocks barrier for zoonotic bat coronavirus infection. J Virol 94:e01774-19. https://doi.org/10.1128/JVI .01774-19.

35. Shang J, Wan Y, Luo C, Ye G, Geng Q, Auerbach A, Li F. 2020. Cell entry mechanisms of SARS-CoV-2. Proc Natl Acad Sci U S A 117:11727-11734. https://doi.org/10.1073/pnas.2003138117.

36. Cockrell AS, Peck KM, Yount BL, Agnihothram SS, Scobey T, Curnes NR, Baric RS, Heise MT. 2014. Mouse dipeptidyl peptidase 4 is not a functional receptor for Middle East respiratory syndrome coronavirus infection. J Virol 88:5195-5199. https://doi.org/10.1128/JVI.03764-13.

37. Webb B, Sali A. 2016. Comparative protein structure modeling using MODELLER. Curr Protoc Bioinformatics 54:5.6.1-5.6.37. https://doi.org/10 .1002/cpbi.3.

38. Hou YJ, Okuda K, Edwards CE, Martinez DR, Asakura T, Dinnon KH, Kato T, Lee RE, Yount BL, Mascenik TM, Chen G, Olivier KN, Ghio A, Tse LV, Leist SR, Gralinski LE, Schäfer A, Dang H, Gilmore R, Nakano S, Sun L, Fulcher ML, Livraghi-Butrico A, Nicely NI, Cameron M, Cameron C, Kelvin DJ, de Silva A, Margolis DM, Markmann A, Bartelt L, Zumwalt R, Martinez FJ, Salvatore SP, Borczuk A, Tata PR, Sontake V, Kimple A, Jaspers I, O'Neal WK, Randell SH, Boucher RC, Baric RS. 2020. SARS-CoV-2 reverse genetics reveals a variable infection gradient in the respiratory tract. Cell 182 429-446.e14. https://doi.org/10.1016/j.cell.2020.05.042. 